\title{
Protection in distributed generation
}

\author{
M.Paz Comech, Miguel García-Gracia, \\ Samuel Borroy and M.Teresa Villén \\ CIRCE (Centre of Research for Energy Resources and Consumption) \\ University of Zaragoza \\ Spain
}

\section{Introduction}

Distributed generation (DG) is related to the use of small generating units installed close to consumption centres. Nowadays, there is an increasing interest in connecting generation to the distribution networks due to the environmental concern increase.

Most protection systems for distribution networks assume power flows from the grid supply point to the downstream low voltage network (Jenkins et al, 2000). Protection is normally based on overcurrent relays with settings selected to ensure discrimination between upstream and downstream relays. A fault on a downstream feeder must be cleared by the relay at the source end of the main feeder. It must not result in the operation of any of the relays on an upstream feeder unless the downstream relay fails to clear the fault. This will result in a blackout in a part of the network that should not have been affected by the fault.

If generation is embedded into the distribution system, the fault current seen by the relay may increase or decrease depending on the location of the relay, the fault and the distributed generators. To ensure an appropriate coordination between relays, grading studies must take into account the maximum and the minimum infeed from all the embedded generators and from the grid supply point.

This chapter describes the protection system problems in distribution systems when connecting distributed generation. First section describes the protection system characteristics in distribution systems without distributed generation, followed by the IEEE requirements for distributed generators under fault conditions (IEEE, 2003). After that the influence of distributed generation on system protection is analysed, taking into account grading, recloser operation and fault detection problems. Fault detection problems are specially relevant for wind turbines. Finally, some conclusions and future solutions that are being developed are described. 


\section{Protection in distribution systems}

The objective of the utilities is to deliver electric energy in a safe, reliable, and economical manner (IEEE 2007). Protective relaying is applied to distribution lines to achieve this objective. The main objectives of a protection system are to detect and respond to all possible types of fault conditions that could occur, while affecting the minimum number of customers, and not limiting the capability of the system to carry load current. Since attempting to accomplish some of these objectives makes it impossible to accomplish others, compromises need to be made. The limits of these compromises are the criteria used to determine locations for the fault-interrupting devices, and the sensitivity and operating speed of the fault detecting devices.

There are different protective schemes applied to distribution systems, the overcurrent protection and the fuse saving/blowing scheme are the most used. These schemes are detailed below.

\subsection{Overcurrent scheme}

Overcurrent protection is the simplest scheme used to protect distribution lines. There are two types of overcurrent relays applied to distribution systems: phase overcurrent and ground overcurrent relays.

These relays can be directional or non-directional depending on system configuration and protection requirements. For radial distribution, non-directional overcurrent relays are applied; while for looped system networks, directional overcurrent relays are more appropriate.

In almost all cases, the distribution feeder protection begins at the substation with feeder breaker or recloser. The recloser is normally equipped with an inverse-time overcurrent device which detects faults and orders the trip of the breaker. Then, after a preset delay, it recloses the breaker. This device should be coordinated upstream with the protection of high voltage transformer and with downstream devices. Downstream devices are generally reclosers or fuses. All of the protective devices placed in series should coordinate on a time current basis with each other in order to minimize the impact of an outage due to a fault. Fig. 1 shows the overcurrent scheme applied in a radial network.

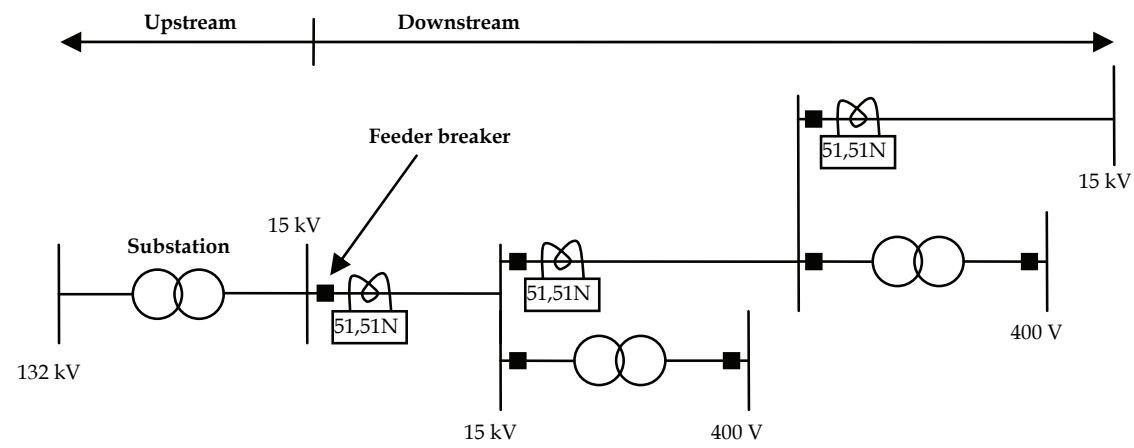

Fig. 1. Overcurrent relays applied to radial distribution network 


\subsection{Fuse saving/blowing schemes}

Protection schemes for distribution feeders based on fuses are generally divided in two types:

a) Fuse saving schemes

b) Fuse blowing schemes

An example system for fuse blowing/fuse saving schemes is given in fig. 2.

Fuse saving schemes are effective on long multi-tapped rural distribution feeders with primarily residential loads that are not as sensitive to momentary outages as industrial loads. In a fuse-saving scheme, breakers or reclosers are set such that they trip before the fuse operates and then automatically reclose (Girgis \& Brahma, 2001). In many cases, faults are only temporary and the line will successfully reclose, causing only a momentary disruption.

Fuse blowing schemes are used to limit the number of main feeder trip reclose cycles in distribution feeders where loads are sensitive to momentary outages and significant disruption occurs if the line is momentarily deenergized. This scheme is often used on feeders serving industrial plants and urban load centres where a number of trip-reclose cycles could result in equipment damage or added risk of personal injury. In this type of schemes, the overcurrent relay or recloser control curves are set above fuse curves such that fuses operate first to clear the faulted line section and the substation device serves as a backup in case the fuse fails, in addition to its function of operating for faults on the main feeder trunk.

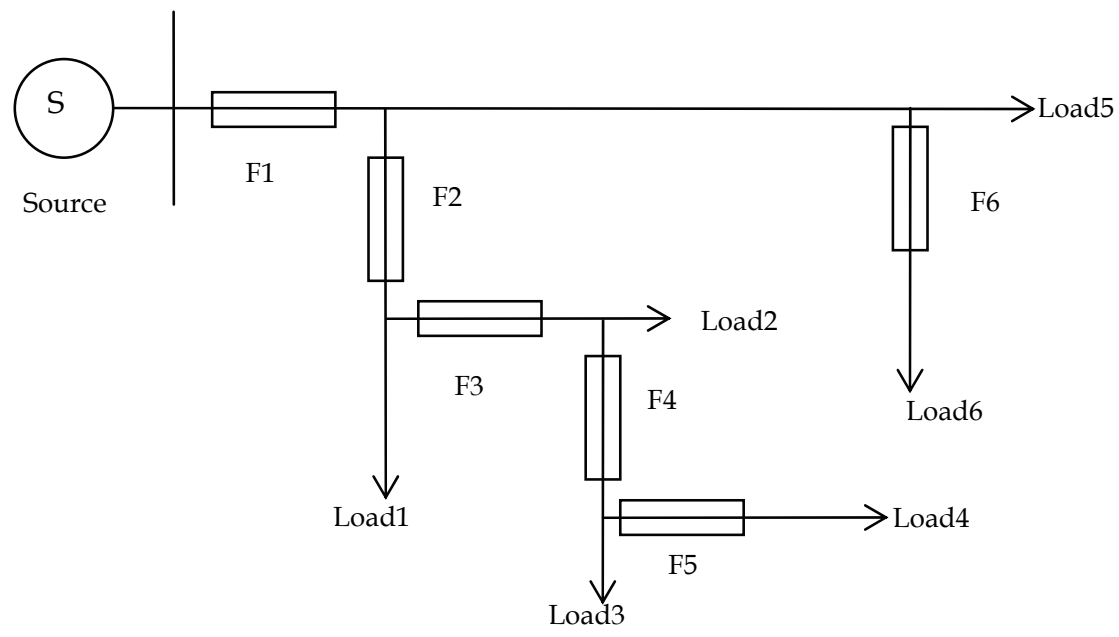

Fig. 2. Example system for fuse scheme 


\section{Requirements for Distributed Resources in Electric Power Systems}

IEEE standard for interconnecting distributed generators with electric power systems (IEEE, 2008) provides interconnection technical specifications and requirements. As it is pointed out in the standard, its existence does not imply that there are no other ways to operate in subjects related to its scope. However it can be assumed as a guide, so standard technical criteria, specially those which involve protection system, are summed up in this section.

\subsection{General requirements}

The following are some of the most relevant general requirements for distributed generators (DGs) specified in the IEEE standard. The requirements involved in fault conditions are described in sections below.

- Voltage requirements: The DGs shall not cause variations in the area electric power system (area EPS) service voltage at other areas.

Grounding: The grounding scheme of the DGs interconnection shall not cause overvoltages that exceed the rating of the equipment connected to the area EPS and shall not affect the coordination of the ground fault protection on that area.

Synchronization: The connection of the DGs shall not cause a voltage fluctuation at the point of common coupling greater than $\pm 5 \%$ of the prevailing voltage level of the area power system at that point.

Area energization: The DGs shall not energize the area power system if it is de-energized.

\subsection{Requirements under fault conditions}

The standard specifies the response of the distribution resources when abnormal conditions, such as faults, arise on the area EPS. According to the standard, the DG units shall cease to energize the area power system for faults on the area circuit to which they are connected. If a fault is detected in a circuit, and the circuit has been de-energized by its protection system in order to clear the fault, no source embebed on the circuit must energize it.

To achieve the interruption of the energization of a faulted circuit and fulfil the standard requirement, the distribution generation unit can be isolated by the following means:

Remote fault detection by the power system circuit protections and subsequent direct transfer trip of the DG unit, using communications.

Local fault detection by the DG unit and subsequent disconnection from the system.

The ability of the DG units to detect external faults depends strongly on the technology of the generator and the type of fault. The behaviour of different types of generators against faults are described next:

Synchronous generator: These units produce fault currents during extended periods of time. The initial fault contribution can reach more than six times the generator full-load current and can decay over several seconds below generator full-load current as the generator field collapses. Furthermore, during the fault, the voltage on the generator is significatively depressed, which can be used to aid in fault detection.

Based on the described current contribution and voltage depression, different methods are commonly used by the DG units based on synchronous generator to detect faults, such as voltage-controlled overcurrent relays and voltage-restrained overcurrent relays. 
Voltage-controlled overcurrent relays are adjusted for a fixed sensitivity. The overcurrent function is enabled only when the voltage is depressed, which is controlled by an undervoltage element. As the sensitivity of the overcurrent relay is a fixed value, the adjusted current must be the minimum magnitude of faults that persist for a long time, which can cause coordination difficulties.

Voltage restrained overcurrent relays can be adjusted at different sensitivity levels depending on the voltage depression. Typically, at $25 \%$ voltage, the sensitivity is four times the one at the rated voltage.

Induction generator and double-fed asynchronous generator: The ability of protective relays to detect faults on the basis of fault-current contribution from this kind of generators depends on the persistence of the fault-current contribution and the required time for relay operation. The persistence of fault current depends on the type of fault (single- or multiphase), the severity of fault, and the means by which the reactive power requirements of the induction generator are supplied.

Due to the importance of these generators, mainly used in wind farms, section 4.3 details their behaviour against faults.

Inverters: Most inverters can not supply important currents under external fault conditions; usually no more than 1.2 to 1.5 times their rated load current. Fault detection schemes using overcurrent principles, which are universally applied, are not usually effective in this case. DG units that use this technology must rely on other methods such as abnormal voltage or frequency sensing to detect faults on the area power system.

In case of external faults, it is clear that the capacity of the distributed generators protections to detect them typically increases with the level of fault current supplied from these energy sources.

On the other hand, the contribution of the DGs to external faults can affect the behaviour of the protections of the area power system. It is a fact that once a DG unit is connected to a power system circuit, it is an energy source that, depending on its type of generator technology, can also supply current to a fault in their evacuation circuit or even in another point of the local power system. The fault-current contribution of the DG unit is the amount of current that the DG will supply to a fault in the circuit. If the DG fault-current contribution is substantial, it will contribute significantly to the total current supplied to the fault. Furthermore, the area power system contribution to the fault will be reduced by the presence of the DG. This may affect the time taken by the protections of the area power system to detect the fault or, in an extreme case, to prevent them from detecting the fault.

\subsection{Requirements on reclosing coordination}

The DG units are required to cease energizing the circuit to which they are connected before any reclosing attempt of that circuit.

Automatic reclosing is widely used in distribution networks in order to clear transient faults and restore the supply with the lower impact. Due to the common radial design in traditional feeders, where the power system is the only source of power, no voltage or synccheck supervisions are needed to perform the reclose attempts. The installation of DGs involves changes on these basic design principles. The assumption that the power system is the only power source for the feeder is invalidated by the presence of disperse generators which can also energize the circuit. In order to avoid an important damage, all DG 
protective devices are required to be carefully coordinated with the recloser of the circuit to which they are connected. If a temporary fault occurs in the feeder and the DG does not trip off and extinguish the fault arc prior to the circuit reclosing attempt, the reclosing attempt will be unsuccessful and the automatic restoration of that circuit may be jeopardized.

\subsection{Requirements under voltage and frequency abnormal conditions}

DG units are required to cease to energize the area power system under some voltage conditions. Table 1 specifies the clearing times required depending on the voltage value.

\begin{tabular}{|c|c|}
\hline $\begin{array}{c}\text { Voltage range } \\
(\% \text { of base voltage })^{\mathrm{a}}\end{array}$ & ${\text { Clearing time }(\mathrm{s})^{\mathrm{b}}}^{\mathrm{V}<50}$ \\
\hline $50 \leq \mathrm{V}<88$ & 0.16 \\
\hline $110<\mathrm{V}<120$ & 2.00 \\
\hline $\mathrm{V} \geq 120$ & 1.00 \\
\hline
\end{tabular}

a Base voltages are the nominal system voltages stated in ANSI C84.1 1995,Table 1

bDG $\leq 30 \mathrm{~kW}$, maximum clearing times; DG $>30 \mathrm{~kW}$, default clearing times.

Table 1. Interconnection system response to abnormal voltages

When the system frequency is in the range given in Table 2, the DG shall cease to energize the area power system within the clearing time indicated (It must be pointed out that the nominal values considered in the standard are based on American system, where nominal frequency is $60 \mathrm{~Hz}$ ).

\begin{tabular}{|c|c|c|}
\hline DG size & Frequency range $(\mathrm{Hz})$ & Clearing time $(\mathrm{s})^{\mathrm{a}}$ \\
\hline \multirow{2}{*}{$\leq 30 \mathrm{~kW}$} & $>60.5$ & 0.16 \\
\hline & $<59.3$ & 0.16 \\
\hline \multirow{3}{*}{$>30 \mathrm{~kW}$} & $>60.5$ & 0.16 \\
\hline & $\begin{array}{c}<\{59.8-57\} \\
\text { (adjustable set point) }\end{array}$ & Adjustable 0.16 to 300 \\
\hline & $<57.0$ & 0.16 \\
\hline
\end{tabular}

${ }^{\mathrm{a} D G} \leq 30 \mathrm{~kW}$, maximum clearing times; DG $>30 \mathrm{~kW}$, default clearing times.

Table 2. Interconnection system response to abnormal frequencies

\section{Influence of Distributed Generation in the protection system}

The interconnection of Distributed Generation (DG) brings a great change to the configuration of the utility distribution network (Yuping Lu, et al. 2007).

As it has been mentioned before, nowadays, the most common configuration in distribution systems is radial. In this type of configurations only one source feeds a downstream network (Girgis \& Brahma, 2001), (Dugan \& Mcdermott, 2002). With the connection of DG, in case of fault, the system can lose the radial configuration, since the DG sources contribute to the fault and therefore, the system coordination could be lost (Girgis \& Brahma, 2001).

The connection of DG in distribution networks must take into account the following subjects: 
- $\quad$ Protection behaviour (coordination problems)

- Adequate ratings of power equipments

- Islanding

- Detection problems

- Operation procedures

The connection of new generation sources in the distribution system modifies the power flow, customer's voltage conditions and the requirements of the utility equipment (Barker\& de Mello, 2000). In a fault situation, distributed generators modify the current contribution to fault, and therefore it influences in the behaviour of network protection (Yuping Lu, et al. 2007), (Girgis \& Brahma, 2001). The influence will depend on the number, type, location and size of DG (Yuping Lu, et al. 2007), (Girgis \& Brahma, 2001). Thus, the characteristics of power equipments and the coordination system, which were established without considering the contribution of distributed generation, must be checked when DG is going to be connected (Yuping Lu, et al. 2007).

The requirements of network power equipments were established in a situation where DG did not exist. In a new situation where DG is present into the system, the initial design may not be adequate because the presence of DG modifies the power flow either in permanent or in fault situation.

On a radial system without DG, the relay protection will see downstream faults because only in that direction will appear power flow. In this situation the fault is cleared opening the breaker of the main feeder because only the main feeder can contribute to the fault. When DG is present in the system, an additional power flow appears from load side to source side and vice versa, therefore the opening of the main feeder breaker does not assure that the fault is cleared (Girgis \& Brahma, 2001), (Dugan \& Mcdermott, 2002).

Another possible situation when DG is connected is the island operation. It is produced when, once the breaker of the main feeder has opened after the fault, the DG continues feeding an isolated part of the network. The islanding is not desirable as it can produce safety and power quality problems in the isolated area. When a DG is working in island, frequency and voltage of this new part of the system can change and damage the system and loads connected in this area. Furthermore, if the distributed generator continues connected during a reclosing, serious damages can appear because of the difference between the grid and the island conditions (voltage, frequency, phase,...) (Barker \& de Mello, 2000).

Another problem related to DG may be the different behaviour, in fault situation, between the different types of generators, in particular between synchronous and asynchronous generators. These differences are explained in section 4.3.

Finally, in areas where the supply depends on distributed generation, if a fault occurs and DG is disconnected following the requirements of IEEE standard (IEEE, 2003), the network could not be able to feed the total load when the utility breaker closes after the fault is cleared. Therefore, changes in operating procedure will be necessary to restore power in these situations (Dugan \&. Mcdermott, 2002). 
In this section coordination problems and automatic reclosing aspects related to the connection of DG to distribution networks are analyzed. Moreover, the behaviour of different types of generators before faults is described.

\subsection{Coordination problems}

In this section, an example illustrates the loss of coordination when DG is connected in a distribution network. First of all, the behaviour of distributed network without considering DG is analyzed, and after that, the loss of coordination due to the connection of DG is shown.

As it has been commented in section 2, the most used protective schemes in distribution networks are fuse blowing and fuse saving schemes. Therefore, an example network is analyzed using both protective schemes.

Case 1: Distribution network protected by fuse blowing schemes (Fuse-Fuse Coordination).

A fuse is characterised by Minimum Melting (MM) and Total Clearing (TC) characteristics. The Minimum Melting characteristic gives the time in which fuse is melted for a given value of fault current and Total Clearing characteristic gives the fault clearing time of fuse considering fault arc extinction for a given value of fault current (Girgis \& Brahma, 2001). Fig. 3 shows the example network protected by fuses.

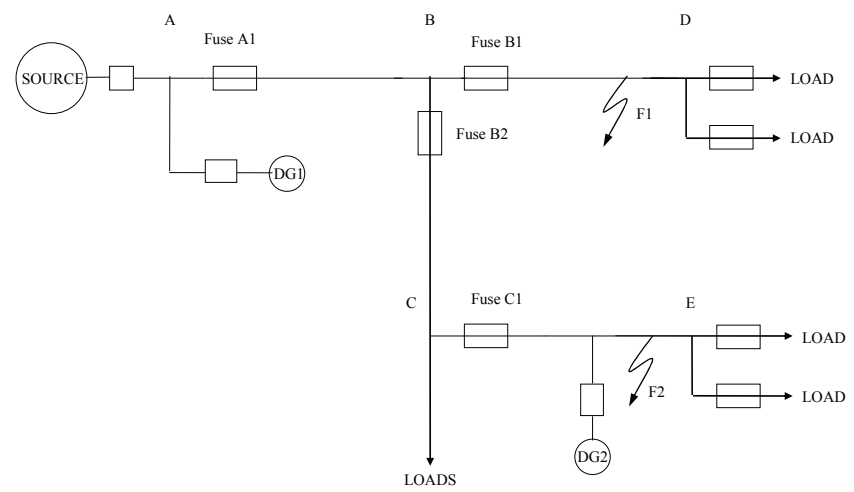

Fig. 3. Fuse blowing scheme

Initially, it is considered that DG is not connected. In this scenario, the network protection is coordinated for a fault on feeder 1 (F1) if both, fuse B1 acts before fuses A1, B2 and C1, and the TC characteristic of fuse B1 is lower than the MM characteristic of fuses A1, B2 and C1 for all range of coordination ( $\left.\mathrm{I}_{\mathrm{fmin}}, \mathrm{I}_{\mathrm{fmax}}\right)$.

Fig. 4 shows the coordination graphic for fuses A1 and B1. 


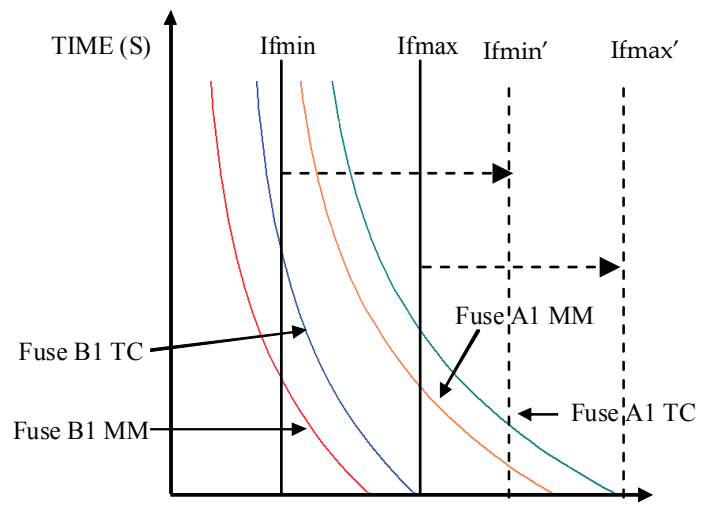

CURRENT (A)

Fig. 4. Coordination graphic of fuses A1 and B1

As it has been commented, when DG is connected in a distributed network, the range of fault current $\left(\mathrm{I}_{\mathrm{fmin}}, \mathrm{I}_{\mathrm{fmax}}\right)$ is modified and current flows in two directions (from source side to load side and vice versa). In this new situation it could happen that the system, initially coordinated, losses the coordination.

To illustrate how DG affects system fault current and system protection behaviour, the distributed network showed in fig. 3 is analyzed for faults in different locations.

- $\quad$ Fault in section BD (Fault F1)

For faults in section BD, the current fault levels, $I_{\mathrm{fmin}}$ and $\mathrm{I}_{\mathrm{fmax}}$, increase because of the presence of generators in source side $\left(\mathrm{I}_{\mathrm{B} 1}=\mathrm{I}_{\mathrm{A} 1}+\mathrm{I}_{\mathrm{B} 2}\right)$.

In this situation, the coordination between fuses could be lost if the increment of current fault makes the range of coordination $\left(\mathrm{I}_{\mathrm{fmin}}{ }^{\prime}, \mathrm{I}_{\mathrm{fmax}}{ }^{\prime}\right)$ exceed the extent of the fuses curves, as it is shown in fig. 4 .

- $\quad$ Fault in section CE (Fault F2)

Fuses C1 and B2 detect downstream and upstream faults. Moreover, the current seen by both of them is always the same. $\left(\mathrm{I}_{\mathrm{B} 2}=\mathrm{I}_{\mathrm{C} 1}\right)$.

In a coordinated system, it is desirable that for faults on feeder 2 (F2), the fuse C1 acts before the fuse B2, and for faults on main line (F1), the fuse B2 acts before the fuse $\mathrm{C} 1$. As the current seen by both of them is the same, this requirement can not be fulfilled.

Case 2: Distribution line protected by fuse saving schemes (Recloser-Fuse Coordination) 


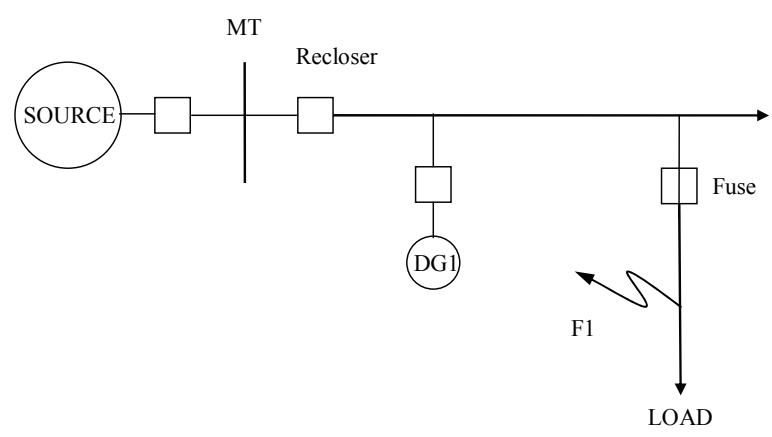

Fig. 5. Fuse saving scheme

Fig. 5 shows a distribution line where the main feeder is protected by a recloser and the load feeder is protected by a fuse. In this configuration the recloser has to act against temporary faults and the fuse against permanent ones.

For the analysis of this configuration, a recloser actuation sequence Fast-Fast-Slow-Slow is supposed. According to this sequence, if faults occur in the load feeder, the recloser acts opening the feeder breaker according to its fast overcurrent curve. The feeder breaker stays in this state for a defined time until the recloser orders to close it, allowing temporary faults to be cleared. If the fault persists, the recloser acts again. If after the second fast actuation of the recloser the fault is not cleared, the fault is assumed to be permanent. Therefore, after the second fast actuation of the recloser, it changes its overcurrent curve to the slow one, so that the fuse acts faster than the recloser. For the correct performance of the described scheme, the recloser and the fuse must be coordinated, as it is shown in Fig. 6.

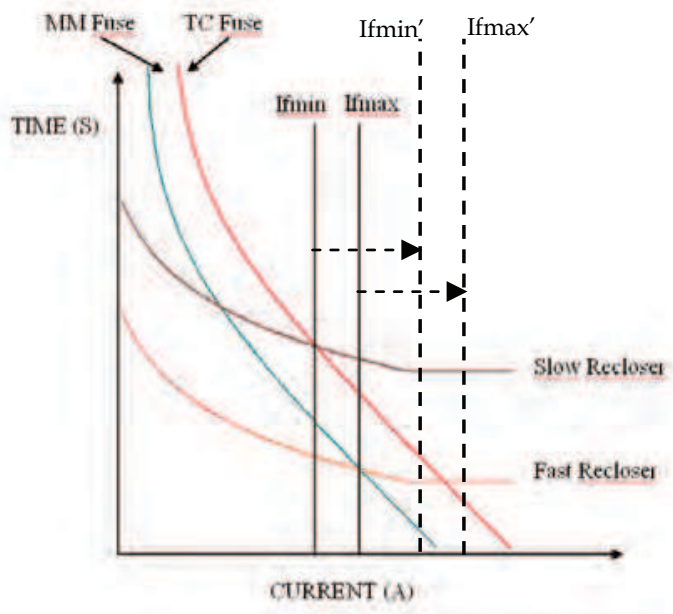

Fig. 6. Characteristics of the fuse (TC and MM) and the recloser (Fast and Slow) for a coordinated system 
As it is showed in Fig. 6, for a fault in the load feeder, if fault current is inside the limits $\left(\mathrm{I}_{\mathrm{fmin}}\right.$ and $I_{\text {fmax }}$ ), the system will be coordinated. From the curves is clear that, in that range of current, fast recloser curve is faster than the fuse one and that the slow recloser is slower than the fuse. If the fuse fails in its actuation, the slow recloser should act as backup protection.

When DG is not connected, the currents seen by the recloser and the fuse for faults in the load feeder are the same so, while current fault is inside coordination range $\left(\mathrm{I}_{\mathrm{fmin}}\right.$ and $\left.\mathrm{I}_{\mathrm{fmax}}\right)$, the system is coordinated, as it is showed in Fig. 6.

Considering that DG is connected, the new situation results into the following changes:

- The minimum and the maximum fault currents for a fault in load feeder are modified because of the presence of DG.

- $\quad$ The fault current seen by the recloser is different to the current seen by the fuse.

If fault level increases due to DG, it could happen that fault currents are outside the coordination range. As it is showed in Fig. 6, in this situation the system loses the coordination because the MM characteristic of the fuse is lower than the fast recloser curve.

The different currents seen by the recloser and by the fuse depend on the size, location and type of DG. This difference of current can cause coordination problems to appear, if the current seen by both protections makes the fuse to act before the fast recloser actuation.

The described problems get worse if intermittency of renewable energy sources, which are mostly used in distributed generators, is considered.

\subsection{Automatic reclosing problems}

For a normal system operation, in a scenario where islanding is not contemplated, as it is recommended in the IEEE Std. 1547 (IEEE, 2003), the correct sequence of events in case of fault is the following (Pregelj et al, 2006):

1. The feeder circuit breaker is tripped, ordered by its protection devices

2. DG connected to the feeder is tripped

3. The recloser reconnects the feeder automatically

4. DG reconnects after normal operating voltage and frequency are established.

As it has been advanced in section 3.3, automatic reclosing is a widely extended practice in distribution networks and, in fact, it is necessary to clear transient faults and restore the supply with the lower impact. Under the basic assumption that upstream substation is the only power source for the distribution feeder, reclosing practices usually do not consider voltage or synchronism supervision, and most of the operators use instantaneous reclosing in distribution networks.

The presence of DG connected to distribution circuits can involve a serious problem for its reclosers performance, as it invalidates the aforementioned assumption. DG could maintain energization of the feeder after the feeder breaker trip. Avoiding potential reclosing problems is one of the main reasons for the IEEE standard requirement (IEEE, 2003) 
according to which, the DG units shall cease to energize the area power system for faults on the circuit to which they are connected.

Effective fault arc extinction may be prevented if the DG units keep energizing the circuit after the feeder breaker trip due to a fault. If the fault is temporary but the DG does not trip, the arc may be maintained even being the feeder breaker opened. In that case, when the reclosing attempt is made, the fault arc is not completely extinguished, so the fault becomes energized again. This involves the failure of the reclosing attempt and the corresponding damage for the system (Conti, 2008).

On the other hand, even if the fault is totally cleared at the moment of reconnection of the feeder circuit breaker, out-of-phase recloses can take place if DG units energize the circuit, since usually no sync check is made in distribution feeders. The problems derived from an out-of-phase reclose may affect both the DG units and the power system:

- In case the DG units connected to the feeder reclosed are rotator generators, they could suffer high electromechanical torques, which could damage them.

- The feeder may be subjected to important transient overvoltages, due to the different voltage phase angles. These overvoltages could not only damage the feeder devices, but also affect the customer systems. Also severe magnetic inrush currents could flow through transformers and motors connected to the feeder.

Two immediate possibilities can be raised to avoid the reclosing problems, regarding the DG units and the reclosers (IEEE, 2008). The first one, according with the IEEE standard and described in section 3.2, is that DG units must trip when a fault occurs in the circuit to which they are connected. At the same time, they should not trip if a fault occurs in other distribution feeders, even although they are next to the feeder. As it is explained in section 3.2, most generation technologies present difficulties to detect faults. In these cases, the DG units may have severe problems to disconnect themselves under fault conditions. The use of communication aided schemes can be a solution for these type of generators since it permits, at the same time that the feeder circuit breaker is tripped, a direct transfer trip to be sent to the DG units connected to the circuit, regardless of whether they have detected the fault or not. The implementation of the standard IEC61850 (IEC, 2003) is going to provide the exchange of information and signals between all devices interconnected to the Ethernet network, so communication schemes shall be favoured and improved. Fig. 7 shows a simplified example of direct transfer trip scheme.

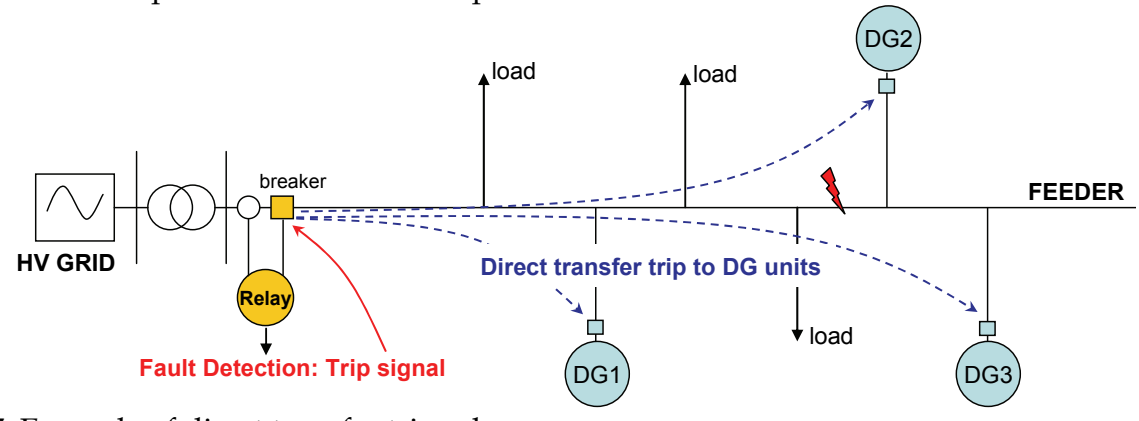

Fig. 7. Example of direct transfer trip scheme 
On the other hand, reclosing schemes may be slightly modified in order to integrate the presence of DG connected to the circuit. A new configuration may include voltage supervision prior to sending the closing order to the breaker, so that the breaker is not closed until the voltage downstream is under a prefixed value. Using the voltage supervision assures that at the reclosing attempt no DG unit is energizing the circuit.

For higher safety, a direct transfer trip scheme like the above explained and a voltage supervision reclosing scheme can be combined.

\subsection{Asynchronous and synchronous generators. Fault detection problems}

One of the main problems in system protection when installing distributed generation is the ability of protective relays to detect external faults, especially in asynchronous generators and in generators connected through converters. This is the case of wind turbines. Fig. 8 shows the most installed configurations of wind turbines.

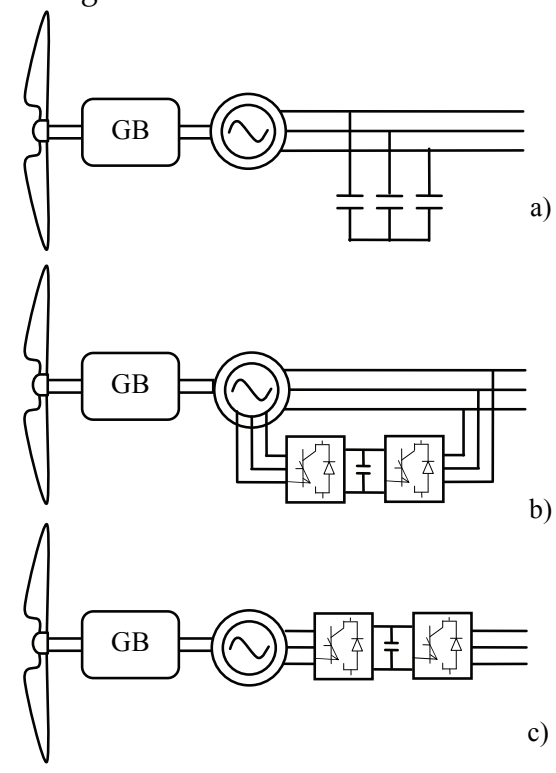

Fig. 8. Wind turbine configuration

Fig. 8a shows the fixed-speed wind turbine with asynchronous squirrel cage induction generator (SCIG) directly connected to the grid via transformer. Fig. $8 \mathrm{~b}$ represents the limited variable speed wind turbine with a wound rotor induction generator and partial scale frequency converter on the rotor circuit known as doubly fed induction generator (DFIG). Fig. 8c shows the full variable speed wind turbine, with the generator connected to the grid through a full-scale frequency converter.

Protection engineering software tools used to set and coordinate the protection system usually do not include wind generator models. Only the synchronous generator model is available in some of them (Electrocon, 2000). This model supposes the short circuit contribution constant and equal to the subtransient short circuit current. Therefore, at the 
present time, there are two options when the protection coordination must be performed in areas with high wind power penetration: to neglect the effects of the wind turbines contribution or to model the asynchronous wind turbine as synchronous generator.

\subsubsection{Wind turbines before short circuit contribution}

Wind turbines contribution to short circuit is analyzed in this section. Fig. 9 shows the current contribution of an SCIG generator.

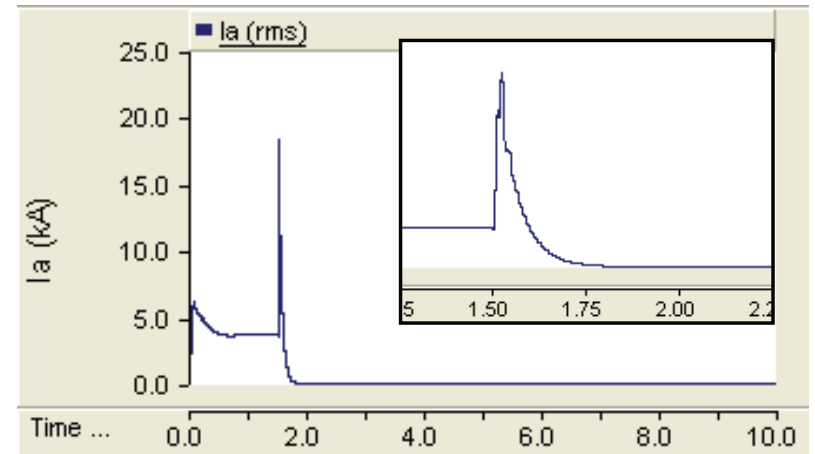

Fig. 9. Asynchronous generator rms current contribution

Unlike synchronous generators, induction generators do not have field windings to develop the required electro-magnetic field in the air gap of the machine, so induction generators can not work without external power supply. Therefore, under fault conditions their air gap flux drops quickly and their contribution to the fault is usually negligible after two or three cycles (Anderson, 1998). During the first cycles the contribution of the asynchronous machine is not despicable (Anderson, 1973), (Das, 2002), therefore, neglecting the induction initial short circuit current could lead to errors in the choice of the protective relaying, switching equipment and phase settings of the protective relaying.

In order to compare, Fig. 10 shows a synchronous generator short circuit current contribution.

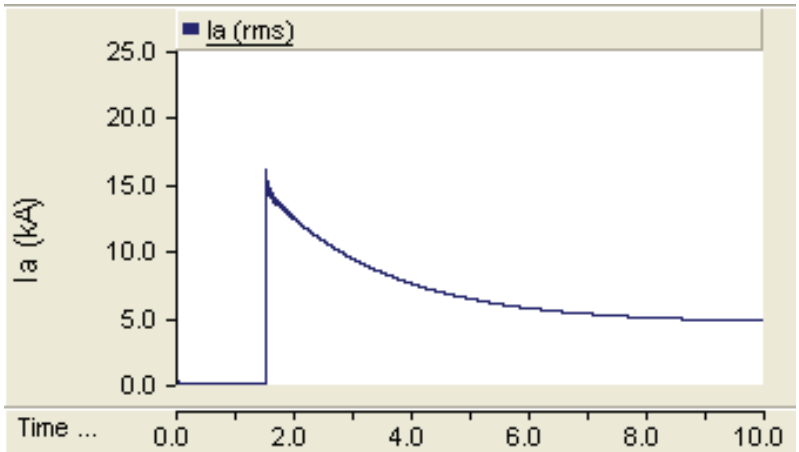

Fig. 10. Synchronous generator rms current contribution 
Comparing both figures, it is observed than the main difference between the short circuit current contributions of a synchronous generator (Fig. 10) and an asynchronous one (Fig. 9) is the speed with which it drops. Then, the detection of the fault by the protective device must be done before the current contribution drops. The response time of the overcurrent relays is around 40 to $60 \mathrm{~ms}$, therefore, if the relay settings for the instantaneous pick up current do not take into account the response time of the relay and the time in which the contribution drops, the protection could not detect the fault.

DFIG stator is connected directly to the network while its rotor is connected to the network by means of a power converter which performs the active and reactive power control. A voltage dip causes large currents in the rotor of the DFIG to which the power electronic converter is connected, so a high rotor voltage will be needed to control the rotor current. When this required voltage exceeds the maximum voltage of the converter, it is not possible any longer to control the desired current (Morren \& de Haan, 2007). This implies that a large current can flow, which could destroy the converter.

In order to avoid breakdown of the converter switches, a crowbar is connected to the rotor circuit. When the rotor currents become too high, the converter is disconnected and the high currents do not flow through the converter but rather into the crowbar resistances. Then the generator operates as an induction machine with a high rotor resistance. When the dip lasts longer than a few hundreds of milliseconds (Tmax_crowbar), the wind turbine can even support the grid during the dip (Morren \& de Haan, 2005).

This behaviour is shown in Fig. 11, a 200 ms short circuit has been simulated. The bold line shows the crowbar state, at $\mathrm{t}=0.5 \mathrm{~s}$, the fault is produced and the crowbar is activated. After Tmax_crowbar ms, the crowbar is deactivated; the rotor is connected to the converter and the control of the converter limits the current contribution to its nominal values.

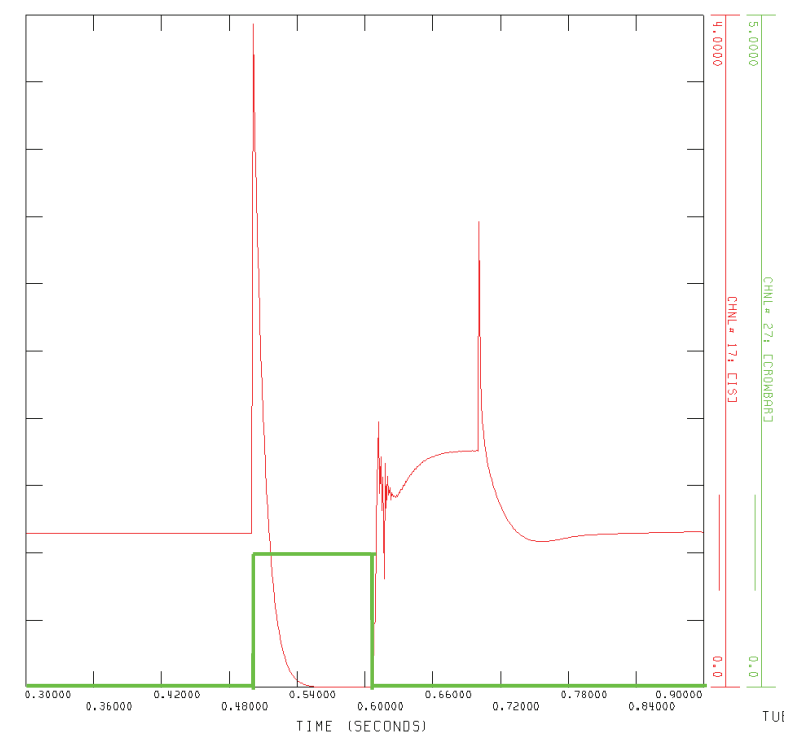

Fig. 11. DFIG rms short circuit contribution 
Full converter contribution depends on the converter behaviour before short circuit. Most converters can not supply important currents under external fault conditions; usually no more than 1.2 to 1.5 times their rated current of the converter. For that reason, it can be modeled as a synchronous generator with the option "Limit Maximum Phase Current" activated. In this case, fault detection schemes using overcurrent principles that are universally applied, are not usually effective. Wind turbines units that use this technology must rely on other methods such as abnormal voltage or frequency sensing to detect faults on the area power system.

\subsubsection{Wind turbine overcurrent protection analysis}

In order to analyse the protection behaviour before wind turbine contribution, and the ability of protection software to model this response, the same network has been modelled in PSCAD/EMTDC and in CAPE to compare the "real" behaviour of the system with the one expected when the protection system is analysed using the models available in protection software tools, with the aim of checking, if the representation of the wind generator as a synchronous generator is valid in this case.

The wind turbine model in PSCAD/EMTDC consists of the asynchronous generator model, the drive train model and the rotor model. The generator and the drive train models have been developed by using the models available in the PSCAD/EMTDC library.

Shaft system influence must not be neglected since the shaft oscillations result in fluctuations of the voltage, machine current, rotor speed and other electrical and mechanical parameters. The shaft system has been modelled by using the PSCAD/EMTDC library multi-mass model. The literature about modelling indicates that a two mass model is adequate to model the drive train in wind turbines (Akhmatov, 2003).

The rotor is a complex aerodynamic system that can be modelled with different detail levels (Petru \& Thiringer, 2002). When electrical behaviour is the main point of interest, an algebraic relation between wind speed and mechanical power extracted is assumed to model the rotor behaviour, which is described by the following equation (Heier, 1998), (Slootweg, 2003):

$$
P=1 / 2 \cdot \rho \cdot A \cdot C p(\lambda) \cdot V_{w}^{3}
$$

Where $\mathrm{P}$ is the power extracted from the wind $[\mathrm{W}], \rho$ the air density $\left[\mathrm{kg} / \mathrm{m}^{3}\right]$; A the swept area $\left[\mathrm{m}^{2}\right]$ and $\mathrm{Vw}$ the wind speed $[\mathrm{m} / \mathrm{s}] . \mathrm{Cp}$ is the performance coefficient that depends on $\lambda$, the tip speed ratio:

$$
\lambda=\frac{\omega_{t u r} R}{V_{w}}
$$

Fig. 12 shows the modelled network and the faults (A, B, C, D and E) simulated in PSCAD/EMTDC; the same network has been modelled in CAPE. The red squares represent the points in which the overcurrent protections are connected. 


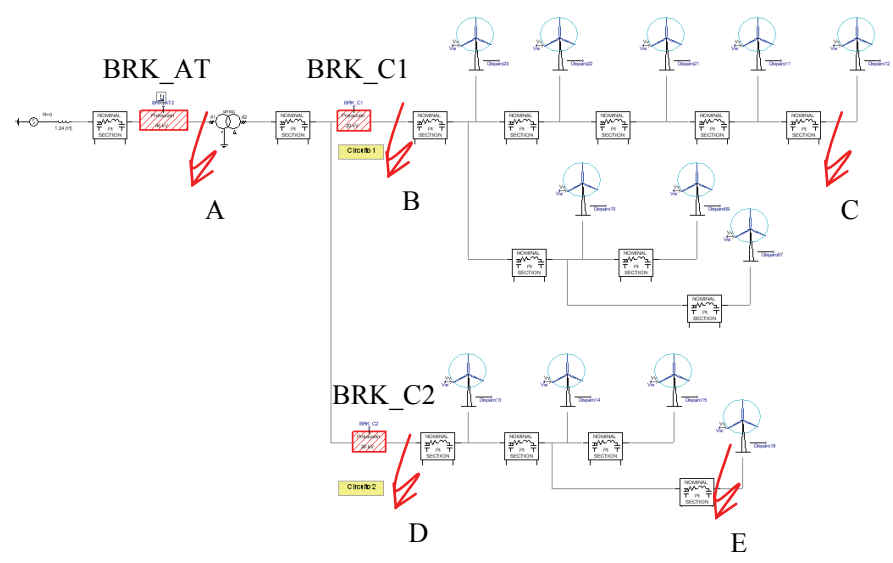

Fig. 12. Modelled network

Fig. 13 shows test A results obtained with CAPE and PSCAD/EMTDC. The value of the current contribution from the wind farm is slightly minor in the PSCAD/EMTDC simulation (109.4 A).
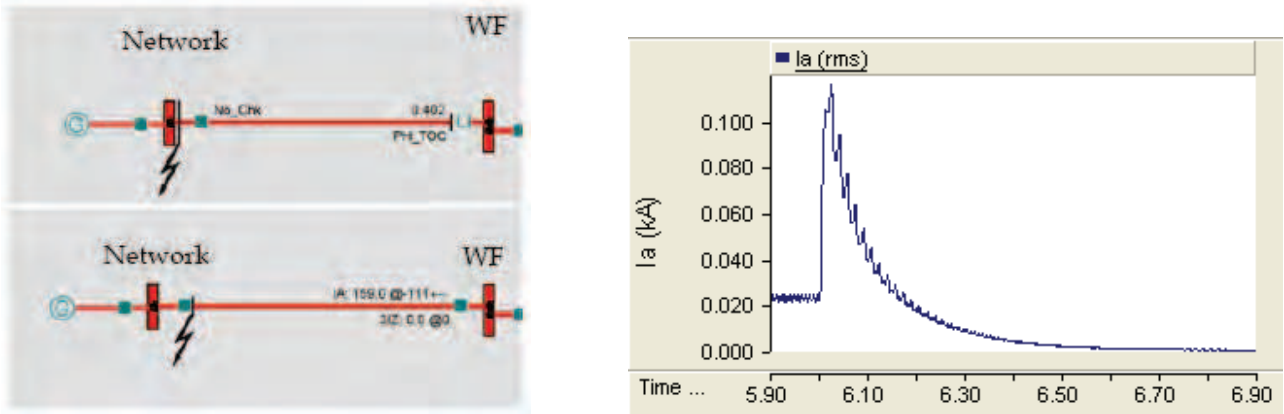

Fig. 13. CAPE and PSCAD results for test $A$

Table 3 shows the comparison between the tripping time obtained by PSCAD/EMTDC and CAPE. Breaker opening time $(60 \mathrm{~ms})$ has been taken into account in these results. When the instantaneous protection operates (tests B, C, D, E) the results obtained by both softwares are similar, with a $15 \mathrm{~ms}$ difference in test $\mathrm{E}$. In test $\mathrm{A}$, the inverse time overcurrent protection (51) operates in CAPE, but, as it has been seen in the previous sections and in Fig. 8, when the trip signal is active in CAPE (0.402-0.06), the short circuit current contribution is almost zero and the real protection would not trip. Therefore, the result obtained by CAPE in test $\mathrm{A}$ is incorrect. 


\begin{tabular}{|l|l|l|l|l|}
\hline & & & CAPE & PSCAD \\
\hline A & BRK_AT & Inverse time & 0,402 & No trip \\
\hline B & BRK_C1 & Instantaneous & 0,090 & 0,0988 \\
\hline C & BRK_C1 & Instantaneous & 0,090 & 0,1013 \\
\hline D & BRK_C2 & Instantaneous & 0,090 & 0,0994 \\
\hline E & BRK_C2 & Instantaneous & 0,090 & 0,1050 \\
\hline
\end{tabular}

Table 3. Overcurrent times by CAPE and PSCAD/EMTDC

For protection system analysis, CAPE recommends the synchronous generator model with the option "Limit Maximum Phase Current" activated to model the wind turbine behaviour. This model can be useful to model the full converted wind turbines (Fig. 8c), since the converter limits the short circuit current to 1.2 or 1.3 times its rated current value. Nevertheless, the DFIG and SCIG short circuit behaviour do not show a good agreement with the shown by this model.

Induction machine short circuit contribution drops after a few cycles, but it is not negligible in this few first cycles. Due to it, wind farm contribution must be taken into account to set the instantaneous overcurrent protection, but not for the inverse time overcurrent protection.

If the asynchronous generator current contribution is neglected, the errors in the instantaneous protection setting can be significant in those zones with high wind power penetration. In case of modelling the asynchronous wind turbine as synchronous generator with a correct value for transitory impedance, like in this analysis, the initial behaviour (first cycles after the fault) is correct, but in few cycles the contribution of the asynchronous generators drops to zero and after those cycles the representation by means of this model no longer is adapted. In that order of time, if the model of synchronous generator is used, the inverse time overcurrent protection would not be coordinated precisely.

One possibility for asynchronous wind turbine modelling is shown in Fig. 14: a synchronous generator model connected to the grid through a switch, which opens 2-3 cycles after the fault. Table 4 shows the results obtained by the different models for tests A and B of the previous example. The behaviour of the proposed model shows a good agreement with the results obtained by PSAD/EMTDC. If the wind turbine contribution is neglected, the instantaneous overcurrent protection operation is not correct. If a synchronous model is used, the inverse curve overcurrent calculation would be wrong.

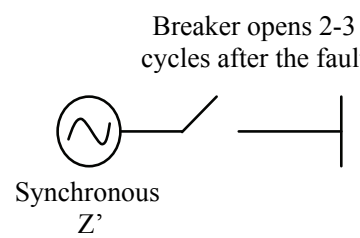

Fig. 14. Proposed model for the protection analysis of asynchronous wind turbines 


\begin{tabular}{|l|l|l|l|l|l|}
\hline \multicolumn{2}{|c|}{} & $\begin{array}{l}\text { Trip time in } \\
\text { CAPE with } \\
\text { the proposed } \\
\text { model }\end{array}$ & $\begin{array}{l}\text { Trip time in } \\
\text { CAPE neglecting } \\
\text { wind turbine } \\
\text { contribution }\end{array}$ & $\begin{array}{l}\text { Trip time in CAPE } \\
\text { with } \\
\text { synchronous } \\
\text { model }\end{array}$ & $\begin{array}{l}\text { Trip time } \\
\text { in PSCAD }\end{array}$ \\
\hline A & Inverse time & Infinite & Infinite & Infinite & 0,400 \\
\hline B & Instantaneous & 0,090 & Infinite & 0,0915 & 0,090 \\
\hline
\end{tabular}

Table 4. Tripping time with the different models

\section{Conclusions and future}

The expectable great penetration of dispersed generators in distribution systems can lead to conflicts with the current protection schemes, since they were designed to work in a different scenario and under different conditions.

Most of the problems described in this chapter would be solved with the implementation of communication schemes and providing the power system with some "intelligence". In this line, the standard IEC61850 and new developments like Smart Grids are expected to bring new tools to integrate DG in distribution systems and overcome the operation problems that could arise otherwise.

Distributed generation integration requires a smart grid to be feasible. This smart grid solves the possible problems that can affect the optimum behaviour of the system by operating the continuous information of the state of the different installations. The smart grid must contribute to the quality and the reliability of the service in the distribution grids as well as to improve the energetic efficiency; nevertheless, the integration of these systems requires a technological effort in automation and communication due to the fact that the exigencies of costs on the distribution systems cannot be comparable to high voltage costs.

Furthermore, the new international standard for communication networks and systems in substation, IEC61850 protocol, is expected to bring a profound evolution in electrical power systems. The new functionalities supported by an intelligent application of IEC61850 must result in a significant improvement of stability and reliability of power system. Smart grids shall take advantage of these features to achieve the commented objectives. Fig. 15 shows an example of communications scheme for a smart grid using IEC61850. 


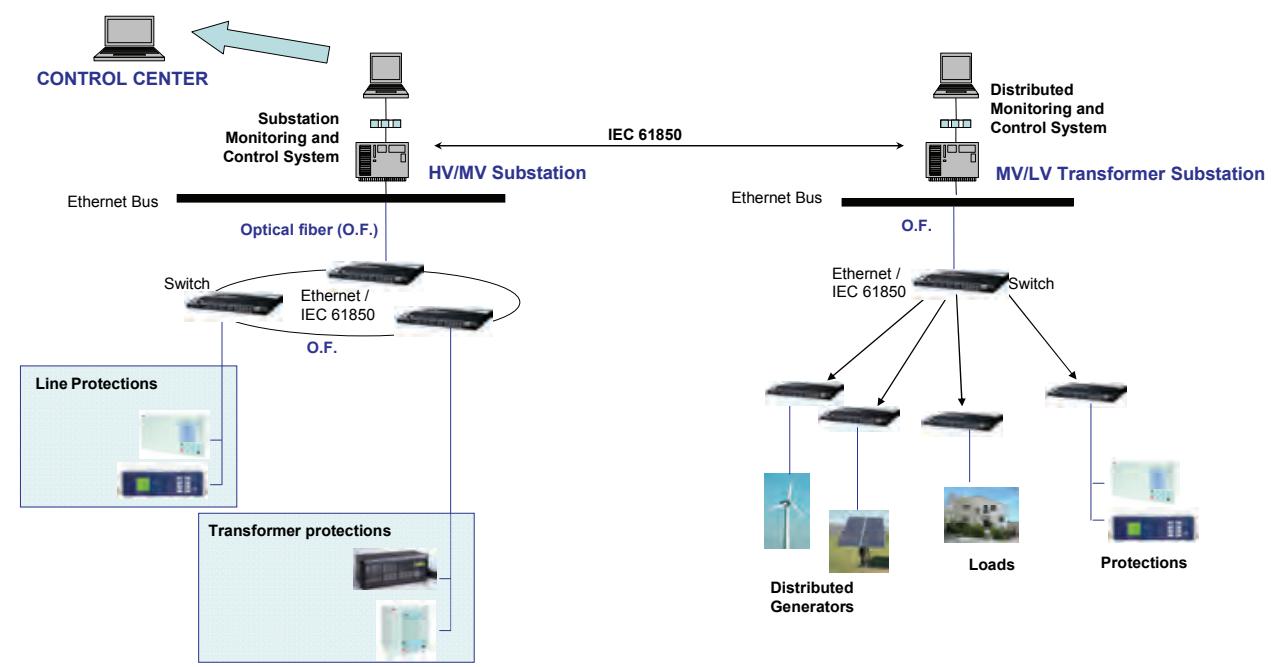

Fig. 15. Communication scheme of a smart grid

\section{References}

Akhmatov, V. (2003), Analysis of Dynamic Behavior of Electric Power Systems with Large Amount of Wind Power, PhD Thesis, 2003

Anderson, P. (1973), Analysis of faulted power systems, Iowa State University Press, 1973

Anderson, P.M. (1998), Power system Protection, IEEE Press, 1998

Barker, P.P. \& De Mello,R.W. (2000). Determining the impact of distributed generation on power systems. I. Radial distribution systems, Proceedings of IEEE Power Engineering Society Summer Meeting, pp.1645-1656 vol.3, 0-7803-6420-1, Seattle,WA, July 2000, Seattle,WA.

Chaitusaney,S. \& Yokoyama,A. (2008). Prevention of Reability Degradation from RecloserFuse Miscoordination Due To Distributed Generation. IEEE Transactions on Power Delivery, Vol. 23, No 4 (Oct. 2008), pp. 2545-2554, 0885-8977.

Conti, S. (2008), Analysis of distribution network protection issues in presence of dispersed generation, Electric Power Systems Research 79 (2009) 49-56.

Das, J.C. (2002), Power system analysis: short circuit, load flow and Harmonics, Marcell Dekker, 2002

Dugan, R.C. \& McDermott, T.E. (2002). Distributed Generation. IEEE Industry Applications Magazine, Vol. 8, No. 2, (March-April 2002), pp. 19-25, 1077-2618.

Eirgrid (2007), Grid Code. Version 3.0, September 2007, http:/ / www.eirgrid.com

Electrocon, (2005), CAPE online help, Ann Arbor, Michigan 2005

Elkraft System, Eltra, (2004), Wind Turbines connected to grids with voltages above $100 \mathrm{kV}$. Technical regulation for the properties and the regulation of wind turbines, Nov. 2004, Regulation T.F.3.2.5. www.enrginet.dk

E.ON Netz (2006), Grid Code. High and extra high voltage, Bayreuth 1 April 2006, http://eon-netz.com 
Girgis, A. Brahma, S. (2001), Effect of distributed generation on protective device coordination in distribution system, Proccedings of Large Engineering Systems Conference on Power Engineering, LESCOPE '01, pp. 115-119, July 2001

Heier, S. (1998), Grid Integration of Wind Energy conversion systems, Chicester, U.K. Wiley 1998

IEC, IEC61850 Standard. Communication Networks and Systems in Substations. Available: http://www.iec.ch.

IEEE Power Engineering Society (2007), IEEE Guide for Protective Relay Applications to Distribution Lines, IEEE Std C37.230TM-2007, ISBN 978-0-7381-5711-5

IEEE (2003), IEEE Standard for Interconnecting Distributed Resources with Electric Power Systems, IEEE Std 1547TM_2003 (R2008), ISBN: 0-7381-3721-9

IEEE (2008), IEEE Application Guide for IEEE Std 1547TM, IEEE Standard for Interconnecting Distributed Resources with Electric Power Systems, IEEE Std 1547.2 ${ }^{\mathrm{TM}}-2008$, ISBN: 978-0-7381-5866-2

Jenkins, N. Allan, R. Crossley, P. Kirschen, D. Strbac, G. (2000) Embedded Generation, The Institution of electrical engineers, ISBN 085296774 8, Herts, United Kingdom

Morren, J., de Haan, S.W.H. (2007) Short-Circuit current of wind turbines with doubly fed induction generator, IEEE Trans. On Energy convers, vol. 22, no. 1, march 2007

Morren, J., de Haan, S.W.H (2005) Ridethrough of wind turbines with doubly fed induction generators during a voltage dip, IEEE Trans. Energy Convers., vol. 20, no. 2, pp. 435-441, Jun. 2005

National Grid Electricity Transmission plc. (2007), The Grid Code, Issue 3, Revision 22, 17 Sept. 2007, www.nationalgrid.com/uk/

Petru, T. Thiringer, T. (2002), Modeling of Wind Turbines for Power Systems Studies, IEEE Transactions on Power Systems, vol 17, NO 4, Nov 2002

Pregelj, P. Begovic, M. Rohatgi (2006), Recloser Allocation for Improved Reliability of DGEnhanced Distribution Networks. IEEE Transactions On Power Systems, Vol. 21, No. 3, August 2006.

Shaw Power Technologies, Inc. (Shaw PTI), Online Documentation PSS/E-29

Slootweg, J.G. Polinder, H. Kling, W.L. (2003), Representing Wind Turbine Electrical Generating Systems in Fundamental Frequency Simulations, IEEE Transactions on Energy Conversion, Vol 18, NO.4, Dec 2003

Verband der Netzbetreiber - VDN (2004), REA generating plants connected to the high and extra high voltage network, August 2004, Berlin, http://www.vdnberlin.de/eeg_hh_en.asp

Yuping Lu; Lidan Hua; Jian Wu; Gang Wu \& Guangting Xu (2007). A Study on Effect of Dispersed Generator Capacity on Power System Protection. Proceedings of IEEE Power Engineering Society General Meeting,2007, pp. 1-6, 1-4244-1296-X, Tampa,FL, June 2007. 


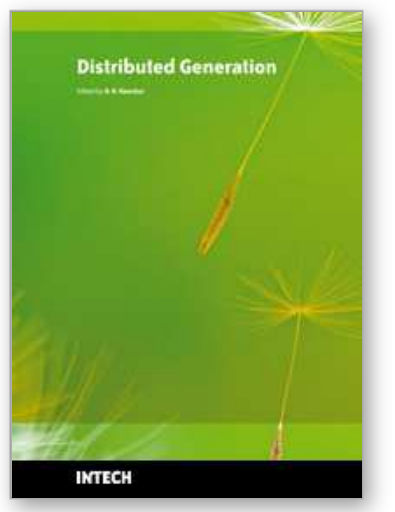

\author{
Distributed Generation \\ Edited by D N Gaonkar
}

ISBN 978-953-307-046-9

Hard cover, 406 pages

Publisher InTech

Published online 01, February, 2010

Published in print edition February, 2010

In the recent years the electrical power utilities have undergone rapid restructuring process worldwide. Indeed, with deregulation, advancement in technologies and concern about the environmental impacts, competition is particularly fostered in the generation side, thus allowing increased interconnection of generating units to the utility networks. These generating sources are called distributed generators (DG) and defined as the plant which is directly connected to distribution network and is not centrally planned and dispatched. These are also called embedded or dispersed generation units. The rating of the DG systems can vary between few $\mathrm{kW}$ to as high as $100 \mathrm{MW}$. Various new types of distributed generator systems, such as microturbines and fuel cells in addition to the more traditional solar and wind power are creating significant new opportunities for the integration of diverse DG systems to the utility. Interconnection of these generators will offer a number of benefits such as improved reliability, power quality, efficiency, alleviation of system constraints along with the environmental benefits. Unlike centralized power plants, the DG units are directly connected to the distribution system; most often at the customer end. The existing distribution networks are designed and operated in radial configuration with unidirectional power flow from centralized generating station to customers. The increase in interconnection of $D G$ to utility networks can lead to reverse power flow violating fundamental assumption in their design. This creates complexity in operation and control of existing distribution networks and offers many technical challenges for successful introduction of DG systems. Some of the technical issues are islanding of DG, voltage regulation, protection and stability of the network. Some of the solutions to these problems include designing standard interface control for individual DG systems by taking care of their diverse characteristics, finding new ways to/or install and control these DG systems and finding new design for distribution system. DG has much potential to improve distribution system performance. The use of DG strongly contributes to a clean, reliable and cost effective energy for future. This book deals with several aspects of the DG systems such as benefits, issues, technology interconnected operation, performance studies, planning and design. Several authors have contributed to this book aiming to benefit students, researchers, academics, policy makers and professionals. We are indebted to all the people who either directly or indirectly contributed towards the publication of this book.

\title{
How to reference
}

In order to correctly reference this scholarly work, feel free to copy and paste the following:

M.Paz Comech, Miguel Garcia-Gracia, Samuel Borroy and M.Teresa Villen (2010). Protection in Distributed Generation, Distributed Generation, D N Gaonkar (Ed.), ISBN: 978-953-307-046-9, InTech, Available from: http://www.intechopen.com/books/distributed-generation/protection-in-distributed-generation 
open science | open minds

InTech Europe

University Campus STeP Ri

Slavka Krautzeka 83/A

51000 Rijeka, Croatia

Phone: +385 (51) 770447

Fax: +385 (51) 686166

www.intechopen.com
InTech China

Unit 405, Office Block, Hotel Equatorial Shanghai

No.65, Yan An Road (West), Shanghai, 200040, China

中国上海市延安西路65号上海国际贵都大饭店办公楼 405 单元

Phone: +86-21-62489820

Fax: +86-21-62489821 
(C) 2010 The Author(s). Licensee IntechOpen. This chapter is distributed under the terms of the Creative Commons Attribution-NonCommercialShareAlike-3.0 License, which permits use, distribution and reproduction for non-commercial purposes, provided the original is properly cited and derivative works building on this content are distributed under the same license. 